\title{
A Retrospective Study of Vertebral Fracture and Luxation in Dogs Presented to University Veterinary Hospital, Universiti Putra Malaysia in 2015 to 2017
}

\author{
Mohd Asri Murshidah", ${ }^{1,2}$, Seng Fong Lau ${ }^{1}$, Saufi Azahari Ikhwan ${ }^{3}$ and Intan Nur \\ Fatiha Shafie $^{1 *}$ \\ ${ }^{1}$ Department of Veterinary Clinical Studies, Faculty of Veterinary Medicine, Universiti Putra Malaysia, \\ 43400 Serdang, Selangor, Malaysia \\ ${ }^{2}$ Faculty of Veterinary Medicine, Universiti Malaysia Kelantan, 16100 Pengkalan Chepa Kelantan, Malaysia \\ ${ }^{3}$ Department of Companion Animal Medicine and Surgery, Faculty of Veterinary Medicine, Universiti Putra \\ Malaysia, 43400 Serdang, Selangor, Malaysia
}

\begin{abstract}
To date, there is data paucity on canine vertebral fracture and luxation (VFL) in the local setting. Therefore, it was hypothesized that the geographical location and stray dog population would influence VFL cases in the University Veterinary Hospital, Universiti Putra Malaysia (UVH, UPM). This study aimed to describe the incidence and characteristics of VFL in dogs presented to UVH, UPM. Medical records, including radiographic images of 74 dogs between 2015 to 2017, were reviewed. VFL dominated the spinal cord disease in dogs at 49\% $(n=36 / 74)$, exceeding intervertebral disc disease (IVDD) and acute noncompressive nucleus pulposus extrusion (ANNPE). Half of VFL cases were contributed by intact male, small breed dogs aged more than one-year-old, with 52\% $(n=11 / 19)$ of cases caused by vehicular accidents. Almost two-thirds $(n=21 / 36)$ of dogs with VFL were outdoor or stray dogs, and the Th3-L3 region was the most susceptible $(52 \%, \mathrm{n}=$

ARTICLE INFO

Article history:

Received: 7 April 2021

Accepted: 27 July 2021

Published: 20 August 2021

DOI: https://doi.org/10.47836/pjtas.44.3.08

E-mail addresses:

ma.murshidah@yahoo.co.uk (Mohd Asri Murshidah)

lausengfong@upm.edu.my (Seng Fong Lau)

ikhwansaufi.azahari@gmail.com (Saufi Azahari Ikhwan)

intannur@upm.edu.my (Intan Nur Fatiha Shafie)

*Corresponding author

19/36) for VFL. More than $70 \%(n=25 / 36)$ of the patients had unstable fractures, highly associated with severity. In conclusion, the occurrence of VFL in UVH, UPM is three times higher than reported in western countries and most likely contributed by a large number of outdoor and stray dogs.

Keywords: Dogs, prognosis, thoracolumbar, vehicular accident, vertebral fracture and luxation
\end{abstract}




\section{INTRODUCTION}

Vertebral fracture and luxation (VFL) is a common spinal cord disorder and constitutes about $7 \%$ of all spinal diseases in dogs (Bali et al., 2009). VFL may affect one or more vertebrae with common lesions reported at the dorsal spinous process, articular facets, and vertebral body (Denny \& Butterworth, 2000; Dyce et al., 2009). Vehicular accidents and high-rise syndrome are major causes of VFL in companion animals represented at $40 \%$ to $60 \%$ (Jeffery, 2010). Fifty per cent $(50 \%)$ of VFL cases in dogs occurred in the thoracolumbar area (Bali et al., 2009; Jeffery, 2010). It is due to the rigid attachment of the ribcage to the thoracic vertebrae through the costovertebral joint with a well-muscled but slightly mobile lumbar area, increasing the region's susceptibility towards VFL (Jeffery, 2010; Zotti et al., 2011). The clinical signs of VFL vary according to the site of the fracture and the degree of spinal cord damage (Hawthorne et al., 1999; Jeffery, 2010). The absence of deep pain perception always suggests a poor prognosis (Bali et al., 2009; Hettlich, 2017; Olby et al., 2003). Most patients are presented with acute and non-progressive signs. However, they may demonstrate progressive symptoms if the fracture is unstable or there is the presence of a haemorrhage (Jeffery, 2010).

The diagnosis of VFL can be achieved by radiograph and/or computed tomography (CT) scan. Plain radiography can detect VFL, but computed tomography provides superior three-dimensional images crucial in surgical planning (Hettlich et al., 2010; Lee \& Thumbikat, 2015; Park et al., 2012).
Magnetic resonance imaging (MRI) is preferred in assessing the intramedullary lesion and soft tissue structures in the adjacent area (da Costa \& Samii, 2010; Gallastegui et al., 2019). Surgical repair is strongly recommended in patients with an unstable fracture with severe spinal pain and neurological dysfunction, although the absence of deep pain sensation tremendously affects the general prognosis (Gallastegui et al., 2019; Jeffery, 2010). Patients with 100\% or more significant vertebral displacement and absence of deep pain have no hope for ambulation (Bagley, 2000; Olby, 2012; Platt, 2008).

The number of studies on VFL in companion animals is limited. The previous reports are centred in the United States, Canada, and European countries (Bali et al., 2009; Bruce et al., 2008; Hawthorne et al., 1999). However, no such report has been established in Asian countries. Therefore, this study aims to describe the incidence, distribution, and clinical characteristics of canine VFL in UVH, UPM.

\section{MATERIALS AND METHODS}

The medical records of dogs presented with spinal cord cases in UVH, UPM were reviewed between January 2015 and December 2017. Basic signalment data include age, breed, sex, body weight, and management. Age was recorded in years and categorised into young $(<1$ year old), adult (1-5 years old), and senior ( $>5$ years old). While gender was classified into intact male, castrated male, intact female, and spayed female. The breeds were grouped 
into small $(1 \mathrm{~kg}$ to $10 \mathrm{~kg})$, medium $(10 \mathrm{~kg}$ to $20 \mathrm{~kg}$ ), and large breed dogs $(20 \mathrm{~kg}$ to $50 \mathrm{~kg}$ ) (Shamir et al., 2002). The detail on the management, such as indoor, outdoor or stray, was also collected. Information on localisation and severity was documented based on neurological examination findings. The lesions were classified according to their location within the vertebral column (C1-C5, C6-Th2, Th3-L3, L4-L7, and S1-S3). Five-point grading system was utilised for each case: $\mathrm{I}$ = pain only; $\mathrm{II}=$ proprioceptive deficits and/or ambulatory para-/tetraparesis; III = non-ambulatory para-/tetraparesis; IV = para-/tetraplegia; $\mathrm{V}$ = para-/ tetraplegia with loss of deep pain perception (Sharp \& Wheeler, 2005). All patients were offered routine diagnostics, including haematology and biochemistry analysis, survey radiography with and without CT or MRI.

A three-compartment model was used in this study to classify unstable fractures (Kinns et al., 2006; Lanz, 2003). The vertebra was divided into the dorsal, middle, and ventral compartments. The dorsal compartment comprises the articular processes, laminae, pedicles, spinous processes, and supporting muscles. The middle compartment includes the dorsal longitudinal ligaments, the dorsal aspect of the intervertebral discs' annulus fibrosus, and the vertebral body's dorsal part. The ventral compartment comprises the vertebral bodies, the lateral and ventral annulus fibrosus, the nucleus pulposus, and the ventral longitudinal ligaments. The fracture is considered unstable if the lesion involves more than one compartment of vertebrae. For VFL cases, cerebrospinal fluid analysis was not typically offered unless concurrent spinal cord conditions were suspected. All data recorded were obtained at the time when the initial diagnosis was made. The descriptive information was tabulated and analysed using GraphPad Prism 7.0 (GraphPad Software, United States of America).

\section{RESULTS}

A total of 122 spinal cord cases were presented to UVH, UPM from January 2015 to December 2017 and 74 cases fit the inclusion criteria. Among these cases, 49\% $(\mathrm{n}=36)$ was diagnosed with VFL through radiographs, CT or MRI, while other spinal cord disorders represented $51 \%$ of the cases; intervertebral disc disease $(\mathrm{n}=32)$, acute non-compressive nucleus pulposus extrusion (ANNPE) $(n=2)$, one case each of fibrocartilaginous embolism, spinal cord neoplasia, discospondylitis, and subarachnoid diverticulum. Due to various reasons, including inadequate history and lack of diagnostic investigation, 48 cases were excluded.

The distributions of VFL cases according to the dog breed are presented in Table 1. Most patients were from local breeds ( $\mathrm{n}=$ 14/36), followed by four cases from Shih Tzu and three cases from Poodle. Miniature Pinscher, Spitz, Siberian Husky, and Terrier dogs contributed eight cumulative VFL cases. The rest of the VFL patients were from various breeds, including Doberman, Chow Chow, French Bulldog, German Shepherd 
Table 1

Breed distribution for vertebral fracture and luxation cases in UVH, UPM from January 2015 to December 2017

\begin{tabular}{lcc}
\hline Breed & No. of cases & Percentage (\%) \\
\hline Local & 14 & 38.9 \\
Shih Tzu & 4 & 11.1 \\
Poodle & 3 & 8.3 \\
Miniature Pinscher & 2 & 5.6 \\
Spitz & 2 & 5.6 \\
Siberian Husky & 2 & 5.6 \\
Terrier & 2 & 5.5 \\
Doberman & 1 & 2.8 \\
Chow Chow & 1 & 2.8 \\
French Bulldog & 1 & 2.8 \\
German Shepherd Dog & 1 & 2.8 \\
Maltese & 1 & 2.8 \\
Pekingese & 1 & 2.7 \\
Pomeranian & 1 & 2.7 \\
\hline
\end{tabular}

Note $. \mathrm{UVH}=$ University Veterinary Hospital; UPM = Universiti Putra Malaysia

Dog, Maltese, Pekingese, and Pomeranian. had a higher proportion of VFL at $58 \%$ The demographic characteristics of VFL are compared to indoor dogs.

summarised in Table 2.

Most of the cases $(n=21)$ involved small dogs, whereas large dogs appeared to be the least affected group $(n=4)$. The majority of VFL cases were represented by senior $(\mathrm{n}=$ $17)$ and adult dogs $(n=15)$, and only four cases were young dogs aged less than one year old. Intact male dogs contributed to the highest number of VFL at $64 \%(n=23)$, with two-thirds of the population coming from small breed dogs $(n=14)$. Both neutered female and male dogs were the least affected group, and they contributed to five cases in total. Furthermore, outdoor and stray dogs
The number of VFL cases caused by vehicular accidents was 19 , followed by 10 cases of high-rise syndrome, and five cases of dog bites (Figure 1). Stepping accident and pathological fracture due to underlying diseases contributed to two cases overall. More than $50 \%(n=19)$ of the lesion occurred at the Th3-L3 vertebral region (Figure 2), with the most susceptible area found at the thoracolumbar junction (Th10-L2). In terms of susceptibility, L4$\mathrm{S} 1(\mathrm{n}=8)$ and C1-C5 $(\mathrm{n}=6)$ areas were recorded as second and third, respectively, after Th3-L3. A higher proportion (71\%; $n$ 
$=17$ ) of fracture cases affected more than one vertebral compartment with vertebral body lesion recorded as the highest (Table $3)$. VFL patients were commonly presented with grade $2(\mathrm{n}=10,28 \%)$ and grade $5(\mathrm{n}$ $=9,25 \%)$ as shown in Table 4 . All grade 5 patients had lesions at Th3-L3 with eight cases of unstable fracture. Among these cases, four patients had abnormalities in micturition.

Table 2

Demographic characteristic of vertebral fracture cases presented in UVH from January 2015 to December 2017

\begin{tabular}{lccccccc}
\hline & Total & \multicolumn{2}{c}{$\begin{array}{c}\text { Small dogs } \\
(<10 \mathrm{~kg})\end{array}$} & \multicolumn{2}{c}{$\begin{array}{c}\text { Medium dogs } \\
(10-20 \mathrm{~kg})\end{array}$} & \multicolumn{2}{c}{$\begin{array}{c}\text { Large dogs } \\
(>21 \mathrm{~kg})\end{array}$} \\
\hline & $\mathrm{n}=36$ & $\%$ & $\mathrm{n}=21$ & $\%$ & $\mathrm{n}=11$ & $\%$ & $\mathrm{n}=4$ \\
Age (year/s old) & & & & & & & \\
Young $(<1)$ & 4 & 14.3 & 3 & 9.1 & 1 & 0 & \\
Adult (1-5) & 15 & 38.1 & 8 & 54.5 & 6 & 25 & 1 \\
Senior $(>5)$ & 17 & 47.6 & 10 & 36.4 & 4 & 75 & 3 \\
Sex & & & & & & & \\
Intact male & 23 & 66.6 & 14 & 63.6 & 7 & 50 & 2 \\
Intact female & 8 & 19.1 & 4 & 36.4 & 4 & 0 & \\
Neutered male & 2 & 0 & & 0 & & 50 & 2 \\
$\begin{array}{l}\text { Neutered } \\
\text { female }\end{array}$ & 3 & 14.3 & 3 & 0 & & 0 & \\
Management & & & & & & & \\
Indoor & 15 & 61.9 & 13 & 9.1 & 1 & 25 & 1 \\
$\begin{array}{l}\text { Outdoor and } \\
\text { stray }\end{array}$ & 21 & 38.1 & 8 & 90.9 & 10 & 75 & 3 \\
\hline
\end{tabular}

Note. $\mathrm{UVH}=$ University Veterinary Hospital; $\mathrm{n}=$ Number of cases 


\section{Causes of vertebral fracture and luxation cases}

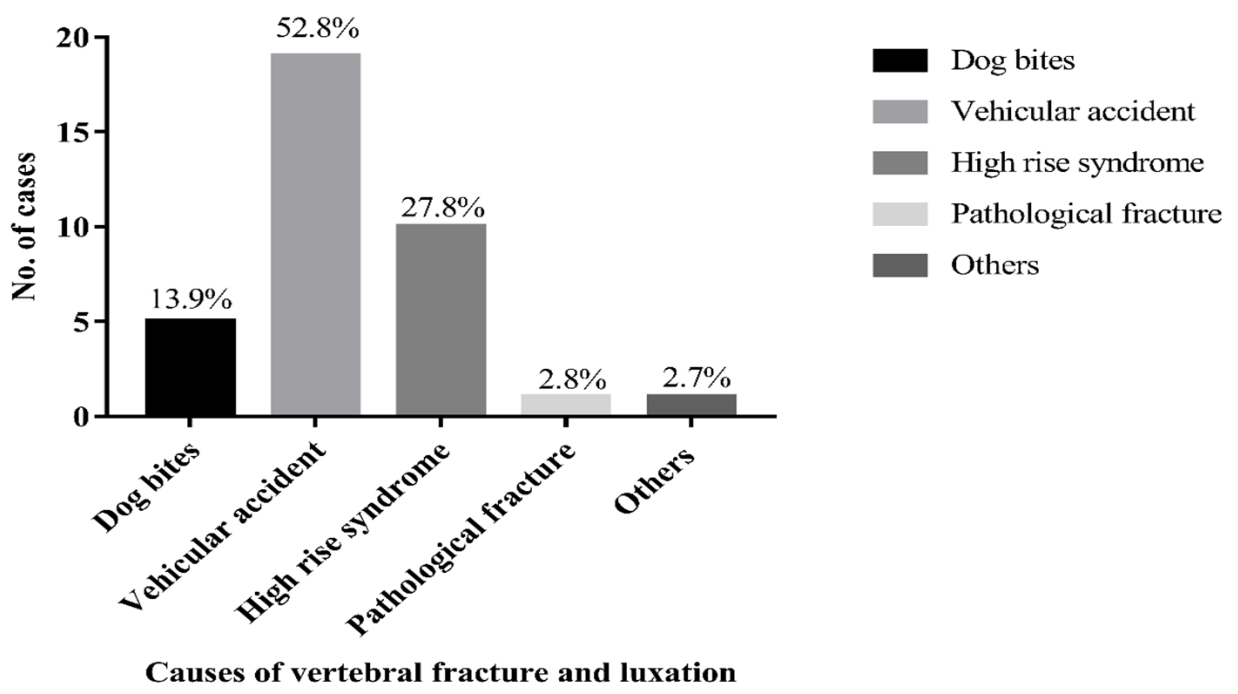

Figure 1. Causes of vertebral fracture and luxation cases recorded in UVH, UPM from 2015- 2017

\section{Lesion localisation in VFL cases}

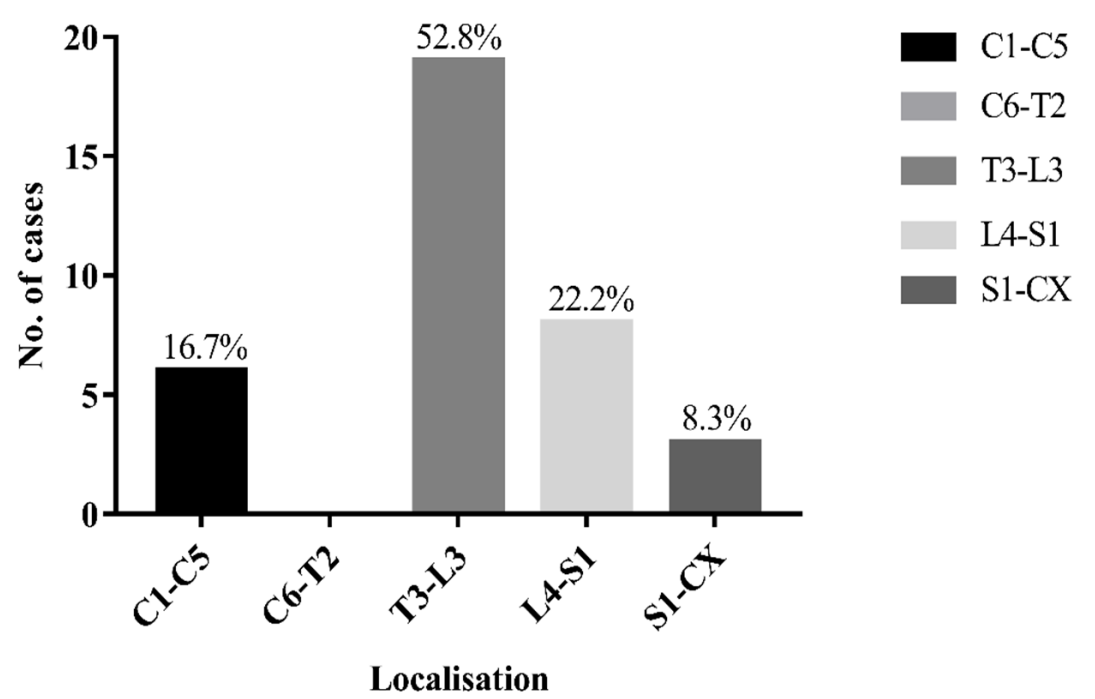

Figure 2. Localisation for vertebral fracture and luxation cases in UVH, UPM from 2015-2017

Note $. \mathrm{VFL}=$ Vertebral fracture and luxation; $\mathrm{C}=$ Cervical $; \mathrm{Th}=$ Thoracic $; \mathrm{L}=$ Lumbar; $\mathrm{S}=\mathrm{Sacrum} ; \mathrm{Cx}=$ coccygeal 
Table 3

Vertebral compartment involvement for fracture cases

\begin{tabular}{llc}
\hline Compartment affected (fracture cases only) & Percentage of cases (\%) \\
\hline Dorsal & $\begin{array}{l}\text { Spinous process dorsal ligamentous structure, } \\
\text { lamina, articular process, and pedicles }\end{array}$ & $2.78 \%$ \\
Middle & $\begin{array}{l}\text { Dorsal longitudinal ligament, dorsal aspect } \\
\text { of vertebral body and annulus fibrosus and } \\
\text { transverse processes }\end{array}$ & $2.78 \%$ \\
Ventral & $\begin{array}{l}\text { Ventral aspect of vertebral body and annulus } \\
\text { fibrosus, nucleus pulposus, and longitudinal } \\
\text { ligament }\end{array}$ & $13.89 \%$ \\
More than one compartment & $70.83 \%$ \\
\hline
\end{tabular}

Table 4

Neurological deficits grading

\begin{tabular}{llcc}
\hline \multicolumn{2}{l}{ Grading } & No. of cases & Percentage of cases (\%) \\
\hline 1 & $\begin{array}{l}\text { Pain with no neurological } \\
\text { dysfunction }\end{array}$ & 6 & $16.67 \%$ \\
2 & $\begin{array}{l}\text { Proprioceptive deficit or } \\
\text { ambulatory paresis or both }\end{array}$ & 10 & $27.78 \%$ \\
3 & Non-ambulatory paresis & 8 & $22.22 \%$ \\
4 & Plegia & 3 & $8.3 \%$ \\
5 & $\begin{array}{l}\text { Plegia with loss of voluntary } \\
\text { urinary function and loss of deep } \\
\text { pain perception }\end{array}$ & 9 & $25 \%$ \\
\hline
\end{tabular}

\section{DISCUSSION}

In this study, VFL was recorded as the most common spinal cord disease at $49 \%$. This finding is inconsistent with previous reports where authors described IVDD as the most familiar spinal cord disease in dogs (da Costa \& Samii, 2010; Denny \& Butterworth, 2000). In two studies conducted in Canada and Switzerland, VFL was recorded between four to eight cases per year (Bali et al.,
2009; Bruce et al., 2008) compared to 12 cases reported per year in UVH, UPM. The vast difference could be contributed by many outdoor and stray dogs in the present study area. The dogs admitted to UVH, UPM were mostly local breed and stray dogs; hence, it is expected to be overrepresented in this study. Despite various breeds in the study, the spinal anatomy between breed, size or age are comparable (Bodh et al., 2016; 
Castañeda-Herrera et al., 2017); thus, it is less likely to affect the nature of the lesion. The extreme forces such as bending, torsion, and shear exerted to the vertebrae also play a significant role in VFL (Albernaz et al., 2016; Park et al., 2012).

Small breed dogs with VFL are present in a large proportion at $58 \%$, and this finding may suggest that these dogs are susceptible to VFL. However, the data was mainly collected in a single institution surrounded by urban areas and could be overpopulated by small breed dogs. Likewise, dogs in adult and senior groups were prone to VFL in this study, consistent with a few studies (Bali et al., 2009; Bruce et al., 2008). Adult dogs are very energetic and still at the stage of exploring their surroundings (Hammerle et al., 2015). Their reactions towards stimuli are quicker than senior dogs. Therefore, it is not a surprise if they are susceptible to VFL. Senior dogs may have poor problemsolving. Their reaction time against stimuli may be slower than young dogs, making them vulnerable to accidents (Hammerle et al., 2015). In this study, puppies had the lowest incidence of VFL as most of them were confined in the house until they were trained.

The numbers of intact male dogs with VFL were higher compared to the neutered male and female dogs. Intact male dogs are aggressive, and their behaviours are usually driven by testosterone (McGreevy et al., 2018; Warnes, 2018). They are also fearless (Warnes, 2018), which may explain the high prevalence of VFL in this group. Furthermore, outdoor and stray dogs were prone to suffer from VFL as these dogs spent most of their time outside without supervision. Stray dogs contributed nine cases, and they are always presented with multiple injuries due to accidents, which increased the incidence of VFL in the outdoor group. More than $50 \%$ of VFL cases were caused by vehicular accidents, as previously reported in other studies (Bali et al., 2009; Di Dona et al., 2016; Olby et al., 2003). High-rise syndrome came second after vehicular accidents, which was most likely contributed by dogs living in condominiums and apartments. Five out of 36 VFL cases were caused by dog bites, which is in line with previous studies where dog bites were mentioned as one of the causes of VFL, but no prevalence was provided (Bali et al., 2009; McKee, 1990).

In this study, most VFL cases concentrated at the Th3 to L 3 region, specifically at the thoracolumbar region (Th10-L2). The thoracolumbar region is recognised as the most mobile junction between the constrictive thoracic part and rigid lumbar part in any dog, making the region more susceptible to VFL (Bali et al., 2009; Jeffery, 2010). The cranial thoracic is a very rigid part due to support from the costochondral junction and ribcage (Jeffery, 2010), which might explain the lack of cases affecting this area. The least affected site was the sacrococcygeal region with three cases only. The area is more associated with cat VFL cases than dogs (Davies \& Walmsley, 2012; Jeffery, 2010). The cats' small size causes them to be entrapped under vehicles during an accident, thus increasing the risk for tail traction instead of dogs. 
The results revealed that almost threequarters of fracture cases were classified as unstable via radiographs. Among these numbers, most of the cases were caused by vehicular accidents, suggesting a high association between vehicular accidents and instability. In addition, classification via radiographs may not be accurate as $\mathrm{CT}$ diagnosis is known to be more sensitive in determining the compartment involved, fracture fragments within the vertebral canal, subluxation, and vertebral canal narrowing (Kinns et al., 2006).

Standard neurological grading for thoracolumbar was used to classify the severity in this study. Most VFL patients were presented with grade 2 and grade 5 at $27 \%$ and $25 \%$, respectively. Almost $90 \%$ of grade 5 patients had fractures in more than one compartment, suggesting that unstable fracture is likely associated with lesion severity. Furthermore, micturition problems are commonly seen in patients with severe grades (Bagley, 2000; Jeffery, 2010; Olby et al., 2003), supported in this study. Patients with urinary problems tend to have a poorer prognosis. However, unfortunately, this study lacks information to corroborate the previous findings (Bagley, 2000; Jeffery, 2010; Olby et al., 2003). Most grade 5 patients were euthanised 24 to 48 hours after losing deep pain perception (Bali et al., 2009; Bruce et al., 2008; Duval et al., 1996).

\section{CONCLUSION}

In conclusion, VFL is the most common cause of spinal cord disease in dogs presented to UVH, UPM. A large population of local and stray dogs contribute to VFL, with $50 \%$ of lesions occurring at Th3-L3. Most of the patients with unstable fractures suffer from severe lesions that carried a poor prognosis. The characterisation of VFL cases in this study can assist in refining the medical and surgical treatment to improve the clinical outcome of VFL cases. However, this data is still limited to a single institution, and the present results should be applied cautiously to other settings.

\section{ACKNOWLEDGEMENTS}

Most tremendous appreciation to Universiti Malaysia Kelantan for sponsoring the first author to continue her study in this field.

\section{CONFLICT OF INTEREST}

The author declares no conflict of interest.

\section{REFERENCES}

Albernaz, V. G. P., Fabris, I. D. A., Paiva, B. R., Coris, J. G. F., \& Quitzan, J. G. (2016). Traumatic spinal cord injury with schiff-sherrington posture and spontaneous resolution in a dog: MRI evaluation. Acta Veterinaria Brasilica, 10(2), 177-181. https://doi.org/10.21708/avb.2016.10.2.5736

Bagley, R. (2000). Spinal fracture or luxation. Veterinary Clinics of North America - Small Animal Practice, 30(1), 133-153. https://doi. org/10.1016/S0195-5616(00)50006-0

Bali, M. S., Lang, J., Jaggy, A., Spreng, D., Doherr, M. G., \& Forterre, F. (2009). Comparative study of vertebral fractures and luxations in dogs and cats. Veterinary and Comparative Orthopaedics and Traumatology, 22(1), 47-53. https://doi. org/10.3415/VCOT-08-02-0018 
Bodh, D., Hoque, M., Saxena, A. C., Gugjoo, M. B., Bist, D., \& Chaudhary, J. K. (2016). Vertebral scale system to measure heart size in thoracic radiographs of Indian Spitz, Labrador retriever and Mongrel dogs. Veterinary World, 9(4), 371-376. https://doi.org/10.14202/ vetworld.2016.371-376

Bruce, C. W., Brisson, B. A., \& Gyselinck, K. (2008). Spinal fracture and luxation in dogs and cats: A retrospective evaluation of 95 cases. Veterinary and Comparative Orthopaedics and Traumatology, 21(3), 280-284. https://doi. org/10.1055/s-0037-1617373

Castañeda-Herrera, F. E., Buriticá-Gaviria, E. F., \& Echeverry-Bonilla, D. F. (2017). Anatomical evaluation of the thoracolumbar nerves related to the transversus abdominis plane block technique in the dog. Journal of Veterinary Medicine Series C: Anatomia Histologia Embryologia, 46(4), 373-377. https://doi.org/10.1111/ahe.12279

da Costa, R. C., \& Samii, V. F. (2010). Advanced imaging of the spine in small animals. Veterinary Clinics of North America - Small Animal Practice, 40(5), 765-790. https://doi. org/10.1016/j.cvsm.2010.05.002

Davies, E., \& Walmsley, G. (2012). Management of tail pull injuries in cats. Companion Animal Practice, 34(January), 27-34. https://doi. org/10.1136/inp.d7449

Denny, H. R., \& Butterworth, S. J. (2000). A guide to canine and feline orthopaedic surgery (4th ed.). Blackwell Science Ltd. https://doi. org/10.1002/9780470699027

Di Dona, F., Della Valle, G., Lamagna, B., Balestriere, C., Murino, C., Santangelo, B., Lamagna, F., \& Fatone, G. (2016). Percutaneous transilial pinning for treatment of seventh lumbar vertebral body fracture. Veterinary and Comparative Orthopaedics and Traumatology, 29(02), 164169. https://doi.org/10.3415/vcot-15-01-0003
Duval, J., Dewey, C., Royce, R., \& Aron, D. (1996). Spinal cord swelling as a myelographic indicator of prognosis : A retrospective study in dogs with intervertebral disc disease and loss of deep pain perception. Journal of Small Animal Practice, 25(1), 6-12. https://doi.org/10.1111/j.1532950x.1996.tb01371.x

Dyce, K. M., Sack, W. O., \& Wensing, C. J. G. (2009). Textbook of veterinary anatomy. Elsevier Health Sciences.

Gallastegui, A., Davies, E., Zwingenberger, A. L., Nykamp, S., Rishniw, M., \& Johnson, P. J. (2019). MRI has limited agreement with CT in the evaluation of vertebral fractures of the canine trauma patient. Veterinary Radiology and Ultrasound, 60(5), 533-542. https://doi. org/10.1111/vru.12785

Hammerle, M., Horst, C., Levine, E., Overall, K., Radosta, L., Rafter-Ritchie, M., \& Yin, S. (2015). 2015 AAHA canine and feline behavior management guidelines. Journal of the American Animal Hospital Association, 51(4), 205-221. https://doi.org/10.5326/jaaha-ms-6527

Hawthorne, J., Blevins, W., Wallace, L., Glickman, N., $\&$ Waters, D. (1999). Cervical vertebral fractures in 56 dogs: A retrospective study. Journal of the American Animal Hospital Association, 35(2), 135-146. https://doi.org/10.5326/15473317$35-2-135$

Hettlich, B. (2017). Vertebral fracture and luxation repair. In A. Shores \& B. A. Brisson (Eds.), Current techniques in canine and feline neurosurgery (1st ed., pp. 209-233). John Wiley \& Sons.

Hettlich, B. F., Fosgate, G. T., Levine, J. M., Young, B. D., Kerwin, S. C., Walker, M., Griffin, J., \& Maierl, J. (2010). Accuracy of conventional radiography and computed tomography in predicting implant position in relation to the vertebral canal in dogs. Veterinary Surgery, 39(6), 680-687. https://doi.org/10.1111/j.1532950X.2010.00697.x 
Jeffery, N. D. (2010). Vertebral fracture and luxation in small animals. Veterinary Clinics of North America - Small Animal Practice, 40(5), 809828. https://doi.org/10.1016/j.cvsm.2010.05.004

Kinns, J., Mai, W., Seiler, G., Zwingenberger, A., Johnson, V., Cáceres, A., Valdés-Martínez, A., \& Schwarz, T. (2006). Radiographic sensitivity and negative predictive value for acute canine spinal trauma. Veterinary Radiology and Ultrasound, 47(6), 563-570. https://doi.org/10.1111/j.17408261.2006.00186.x

Lanz, O. I. (2003). Vertebral fractures and luxations. In Small animal surgery secrets ( $2^{\text {nd }}$ ed., $p$. 360-365). Hanley \& Belfus, Inc. https://doi. org/10.1016/B978-1-56053-579-9.50096-2

Lee, J., \& Thumbikat, P. (2015). Pathophysiology, presentation and management of spinal cord injury. Surgery, 33(6), 238-247. https://doi. org/10.1016/j.mpsur.2015.04.003

McGreevy, P. D., Wilson, B., Starling, M. J., \& Serpell, J. A. (2018). Behavioural risks in male dogs with minimal lifetime exposure to gonadal hormones may complicate population-control benefits of desexing. PLOS One, 13(5), e0196284. https:// doi.org/10.1371/journal.pone.0196284

McKee, W. M. (1990). Spinal trauma in dogs and cats: A review of 51 cases. The Veterinary Record, 126(12), 285-289.

Olby, N. (2012). Spinal trauma. In S. Platt \& L. Garosi (Eds.), Small animal neurological emergencies (pp. 383-397). CRC Press.

Olby, N., Levine, J., Harris, T., Muñana, K., Skeen, T., \& Sharp, N. (2003). Long-term functional outcome of dogs with severe injuries of the thoracolumbar spinal cord: 87 cases (19962001). Journal of the American Veterinary Medical Association, 222(6), 762-769. https:// doi.org/10.2460/javma.2003.222.762
Park, E. H., White, G. A., \& Tieber, L. M. (2012). Mechanisms of injury and emergency care of acute spinal cord injury in dogs and cats. Journal of Veterinary Emergency and Critical Care, 22(2), 160-178. https://doi.org/10.1111/j.14764431.2012.00723.x

Platt, S. (2008). Disorders of the spinal cord. In Handbook of small animal practice (pp. 256274). Elsevier.

Shamir, M. H., Leisner, S., Klement, E., Gonen, E., \& Johnston, D. E. (2002). Dog bite wounds in dogs and cats: A retrospective study of 196 cases. Journal of Veterinary Medicine Series A: Physiology Pathology Clinical Medicine, 49(2), 107-112. https://doi. org/10.1046/j.1439-0442.2002.jv416.x

Sharp, N. J. H., \& Wheeler, S. J. (2005). Diagnosis and surgery. In Small animal spinal disorders (2nd ed., pp. 19-33). Mosby-Wolfe.

Warnes, C. (2018). An update on the risks and benefits of neutering in dogs. The Veterinary Nurse, 9(3), $150-155$.

Zotti, A., Gianesella, M., Gasparinetti, N., Zanetti, E., \& Cozzi, B. (2011). A preliminary investigation of the relationship between the "moment of resistance" of the canine spine, and the frequency of traumatic vertebral lesions at different spinal levels. Research in Veterinary Science, 90(2), 179-184. https://doi.org/10.1016/j. rvsc. 2010.05 .036 
